\title{
KONTROL ARAH GERAK WEB KAMERA (WEBCAM) BERBASIS WEB
}

\author{
Christian Mauko', Semayatri Tunliu²
}

\begin{abstract}
Abstrak :
Komunikasi antar banyak webcam dengan satu webcam pada awalnya diadopsi secara komersil dengan bantuan teknologi yang agresif dimana penggunaannya kebanyakan oleh industri pornografi. Web camera adalah sebuah periferal berupa kamera sebagai pengambil citra/gambar dan mikropon (optional) sebagai pengambil suara/audio yang dikendalikan oleh sebuah komputer atau oleh jaringan komputer. Web camera sendiri memiliki kelebihan selain harganya terjangkau murah, sekarang pada laptop, handphone juga dapat dijadikan sebagai webcam. Motor stepper adalah perangkat elektromekanis yang bekerja dengan mengubah pulsa elektronis menjadi gerakan mekanis diskrit. Arduino merupakan rangkaian elektronik yang bersifat open source, serta memiliki perangkat keras dan lunak yang mudah untuk digunakan. Web sangat mempermudah dengan penggunaannya yang dapat diakses kapanpun dan dimanapun selama mesin kita terhubung oleh jaringan internet salah satunya, format penggunaan web terbuka untuk semua platform serta terbuka dan memiliki dukungan interface yang stabil.
\end{abstract}

Kata Kunci : Webcam, Motor Stepper, Arduino, Web.

\section{PENDAHULUAN}

Teknologi kamera berawal dari sejarah fotografi kuno dimana sudah tercatat sebelum Masehi. Gambar dua dimensi yang dihasilkan dari peran cahaya. Perkembangan teknologi kamera sejak ditemukannya gejala refleksi pemandangan terbalik pada abad ke-5 sebelum Masehi, oleh seorang pria bernama Mo Ti. Kemudian, pada abad ke-10 Masehi, seorang Arab bernama Ibn Al-Haitham (fenomena sama) fotografi lalu tercatat dimulai resmi pada abad ke-19. Dimulai pada 1991, webcam yang pertama di departemen ilmu pengetahuan komputer dari Cambridge University. Seperti halnya banyak teknologi yang baru, komunikasi antar banyak webcam dengan satu webcam pada awalnya diadopsi secara komersil dengan bantuan teknologi yang agresif dimana penggunaannya kebanyakan oleh industri pornografi. Pengembang mengembangkan perangkat lunak agar komunikasi antar webcam tidak lagi memerlukan browser web plugin. Perkembangan teknologi webcam dapat di hubungkan melalui wireless.

Web camera adalah sebuah periferal berupa kamera sebagai pengambil citra/gambar dan mikropon (optional) sebagai pengambil suara/ audio yang dikendalikan oleh sebuah komputer atau oleh jaringan komputer. Motion sensing web camera akan mengambil gambar ketika kamera mendeteksi gerakan. Image archiving pengguna dapat membuat sebuah arsip yang menyimpan semua gambar dari web camera atau hanya gambar-gambar tertentu saat interval preset. Video messaging - beberapa program messaging mendukung fitur ini. Advanced connections - menyambungkan perangkat home theater ke web camera dengan kabel maupun nirkabel. Automotion - kamera robotik yang memungkinkan pengambilan gambar secara pan 
atau tilt dan pengaturan program pengambilan frame berdasarkan posisi kamera. Streaming media - aplikasi profesional, setup web camera dapat menggunakan kompresi MPEG4 untuk mendapatkan streaming audio dan video yang sesungguhnya. Custom coding - mengimport kode komputer pengguna untuk memberitahu web camera apa yang harus dilakukan (misalnya automatically refresh). AutoCam - memungkinkan pengguna membuat web page untuk web cameranya secara gratis di server perusahaan pembuat web camera. Web camera sendiri memiliki kelebihan selain harganya terjangkau murah, sekarang pada laptop, handphone juga dapat dijadikan sebagai webcam.

Motor stepper adalah perangkat elektromekanis yang bekerja dengan mengubah pulsa elektronis menjadi gerakan mekanis diskrit. Motor stepper bergerak berdasarkan urutan pulsa yang diberikan kepada motor. Karena itu, untuk menggerakkan motor stepper diperlukan pengendali motor stepper yang membangkitkan pulsa-pulsa periodik.

Arduino merupakan rangkaian elektronik yang bersifat open source, serta memiliki perangkat keras dan lunak yang mudah untuk digunakan.Arduino dapat mengenali lingkungan sekitarnya melalui berbagai jenis sensor dan dapat mengendalikan lampu, motor, dan berbagai jenis aktuator lainnya.Arduino mempunyai banyak jenis, diantaranya Arduino Uno, Arduino Mega 2560, Arduino Fio, dan lainnya.

Web sangat mempermudah dengan penggunaannya yang dapat diakses kapanpun dan dimanapun selama mesin kita terhubung oleh jaringan internet salah satunya, format penggunaan web terbuka untuk semua platform serta terbuka dan memiliki dukungan interface yang stabil.

\section{TINJAUAN PUSTAKA}

Untuk penelitian ini penulis telah melakukan beberapa kajian atas penelitian terdahulu yang relevan dengan penelitian penulis, yaitu : a.Zuhro, dkk. (2013). Perancangan dan realisasi model sistem pemantauan ruangan menggunakan webcam berbasis mikrokontroler
ATMega16. Pada model sistem ini, dikembangkan pula program motion detection untuk mendeteksi adanya pergerakan di dalam ruangan. Jika terjadi pergerakan, maka tampilan gambar dari webcam akan direkam pada PC, dan mikrokontroler akan mengaktifkan buzzer. Karena webcam memiliki keterbatasan pencahayaan ketika ruangan gelap, maka dilakukan penambahan modul infra merah yang dilengkapi sensor LDR. Dengan modul ini, pergerakkan di dalam ruangan yang gelap dapat terdeteksi sejauh $6 \mathrm{~m}$. Untuk jarak antara ruang pengawas dan ruang yang dipantau, didapatkan panjang kabel sejauh $10 \mathrm{~m}$.

b.Mustofa (2008). Pemantauan gerakan pada ruangan menggunakan webcam dan motor stepper. Metode yang digunakan adalah deteksi gerakan. Keadaan inilah yang dimanfaatkan untuk di aplikasikan menjadi suatu sistem keamanan. Untuk mendapatkan nilai RGB yang lebih besar maka obyek yang ditangkap oleh kamera harus bercahaya. Dengan nilai RGB yang semakin besar maka pendeteksian gerakan akan lebih mudah. Pendeteksian gerakan dinyatakan aktif jika alarm telah berbunyi. Bunyi alarm disertai dengan putaran motor stepper yang menggerakan kamera untuk mengikuti letak obyek yang bergerak. Putaran motor stepper dikontrol oleh PC (personal computer) melalui port paralel. Proses pengikutan letak obyek akan berhenti jika obyek telah tidak terdeteksi oleh kamera atau aplikasi dimatikan.

\section{METODE PENELITIAN}

\section{a. Metode Pustaka}

Metode Pustaka : yakni dengan melakukan studi pustaka dengan mengumpulkan datadata terhadap semua sumber informasi dalam media cetak, baik itu buku-buku atau modul dari mata kuliah yang telah didapatkan pada perkuliahan dan pemanfaatan media Internet guna mengumpulkan data dan informasi yang diperlakukan. 
b.Metode Eksperimen

Metode Eksperimen : yakni dengan melaksanakan proses perancangan dan pengujian alat.

c. Model Perancangan Sistem

Adapun alat dan bahan yang digunakan dalam proses perancangan adalah sebagai berikut :

Analisa Kebutuhan

\section{a.Alat}

Perangkat keras yang dibutuhkan adalah:

1) Papan akrilik untuk dudukan motor stepper

2) Bor Listrik dengan tegangan $5 \mathrm{~V}$

3) Solder

4) Baut

5) Toples (Dudukan bagian Bawah)

6) Motor Stepper \& Driver

Spesifikasi dari Motor Stepper dan Driver: a)Merek/Tipe: Motor Stepper 28BYJ-48

b)Tegangan :5V DC

c)Merek/Tipe: Driver IC ULN2003

d)Tegangan : 5-12 Volt

7) Kabel Jumper

8) Arduino

Spesifikasi Papan Arduino Uno:
a)Merek
: Arduino Uno
b)Mikrokontroler
: Atmega328
c)Tegangan Operasi
$: 5 \mathrm{~V}$
d)Tegangan Input
: $7-12 \mathrm{~V}$
e)Batas Tegangan Input : 6-20V
9) Kabel USB (Standar A-B)
10) Laptop

Spesifikasi laptop :
a)Sistem Operas
: Windows 7
b)Memori
: RAM 4GB

11) Webcam

Spesifikasi dari kamera :
a)Merek
: M-tech WB100
b)Resolusi
: $2 \mathrm{MP}$
c)Aplikasi Tambahan: Manual Capture, Microphone

\section{b.Bahan}

Software atau perangkat lunak yang dibutuhkan adalah :
1) Sistem Operasi yang digunakan adalah Windows 7

2) Arduino

3) Processing

4) Tincam

5) XAMPP

6) Notepad++ untuk teks editor PHP (Hypertext Preprocessing)

\section{c.Prosedur perancangan sistem}

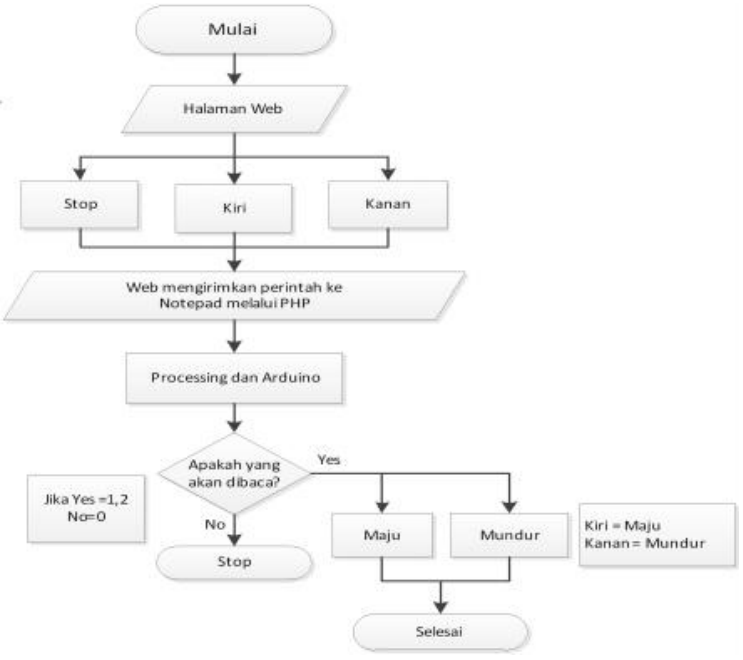

Gambar 1. Flowchart Perancangan

\section{d.Arsitektur sistem}

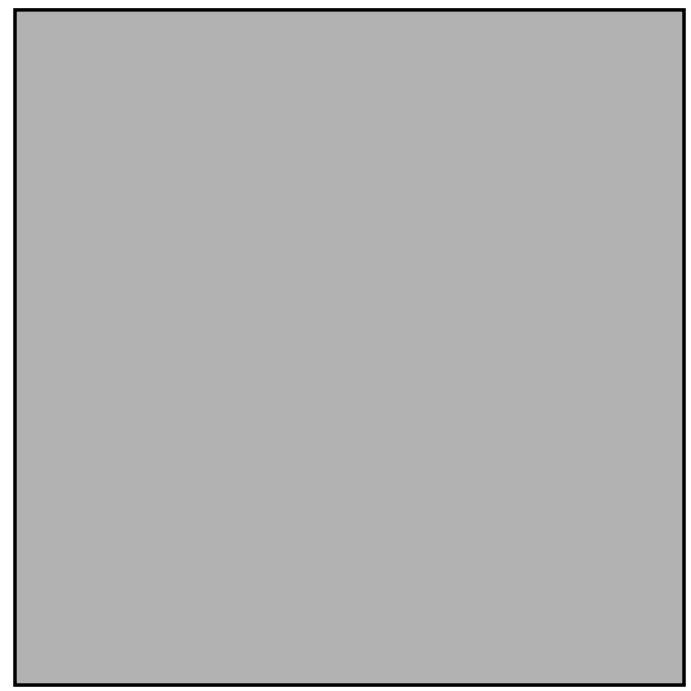

Gambar 2. Arsitektur Sistem 
e.Desain Interface

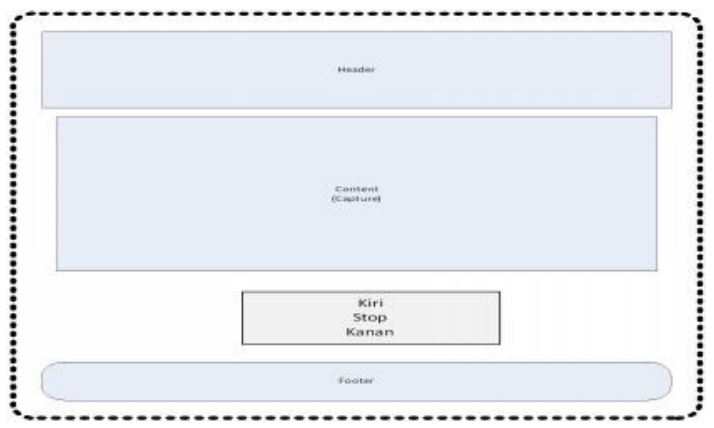

Gambar 3. Desain Interface

\section{f. Teknik Pengujian system}

Teknik pengujian awal dengan pengujian untuk motor stepper terhadap rotater yang di atur perputarannya setelah selesai pengujian pada motor stepper maka dilanjutkan pada pengujian fungsi kamera melakukan pemantauan ruangan menggunakan hasil capture yang mana ditampilkan pada web yang telah desain.

\section{HASIL DAN PEMBAHASAN}

\subsection{Hasil}

4.1.1. Implementasi Arduino

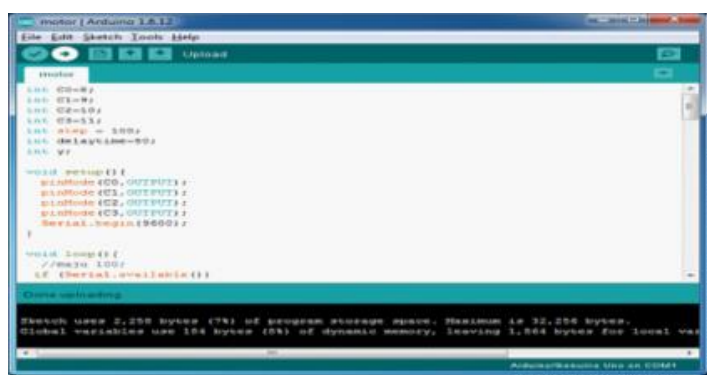

Gambar 4. Tampilan Implementasi Arduino

4.1.2. Hasil Implementasi Processing

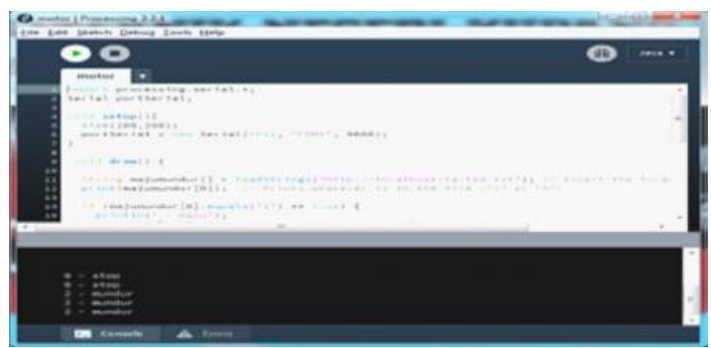

Gambar 5. Tampilan Implementasi Processing
4.1.3. Hasil Implementasi Notepad

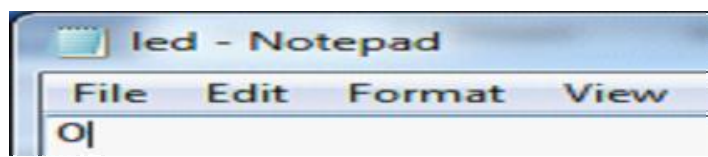

Gambar 6. Tampilan Implementasi Notepad 4.1.4. Hasil Implementasi Tincam

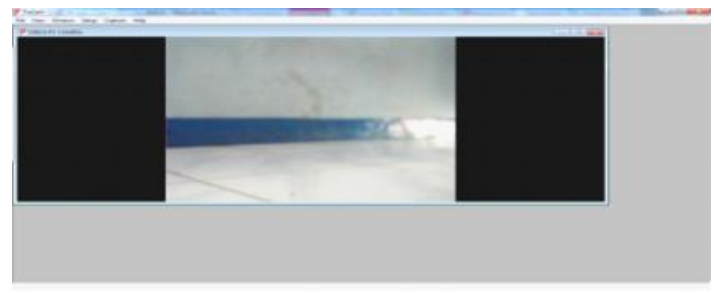

Gambar 7. Tampilan Implentasi Tincam

4.1.5. Hasil Implementasi Interface

1.Hasil Implementasi Kontrol Gerak Kamera

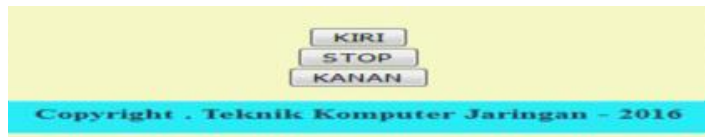

Gambar 8. Tampilan Implementasi Kontrol Gerak Kamera

2. Hasil Implementasi Web

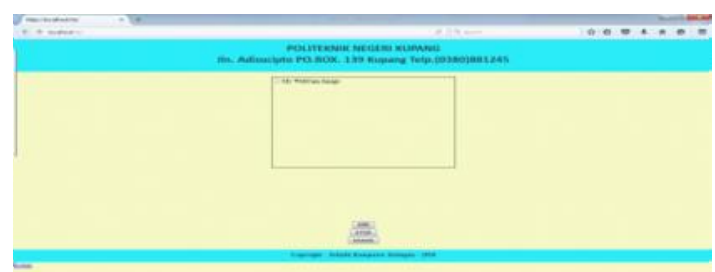

Gambar 9. Tampilan Implementasi Halaman web

\subsection{Pembahasan}

\subsubsection{Pembuatan atau Perakitan Alat}

Pada pembuatan atau perakitan alat, alat dan bahan yang perlu dipersiapkan adalah sebagai berikut : 


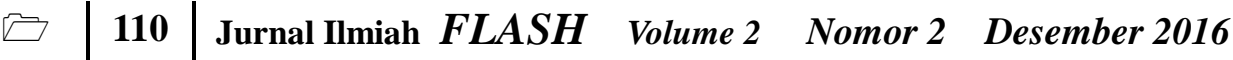

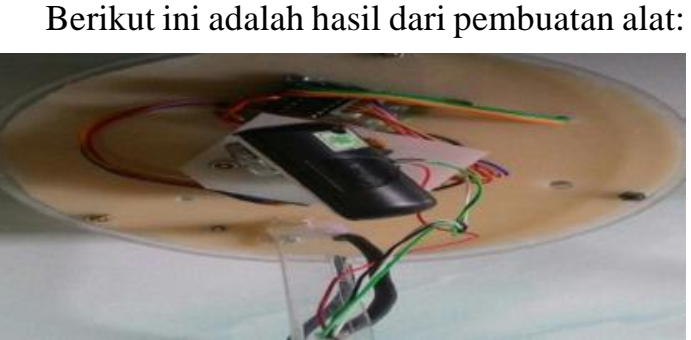

Gambar 10. Tampilan alat bagian atas

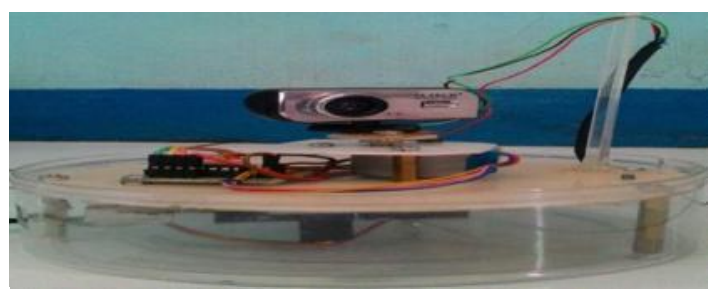

Gambar 11. Tampilan alat bagian samping

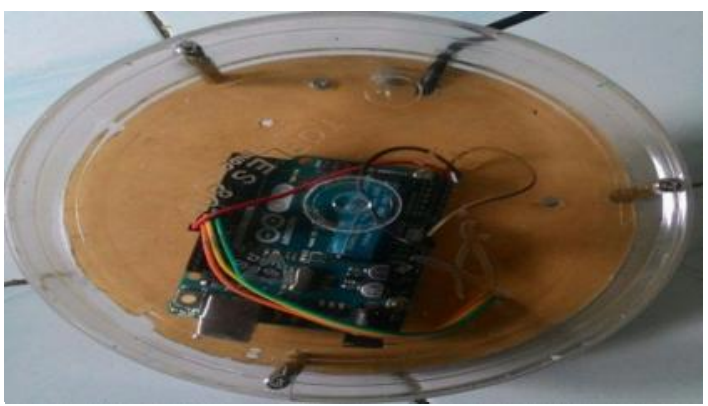

Gambar 12. Tampilan alat bagian bawah

4.2.2. Pembahasan Aplikasi

\subsubsection{Pembuatan Program pada arduino}

Pada Program arduino sendiri dituliskan program untuk menjalankan motor. Penulisannya adalah sebagai berikut :

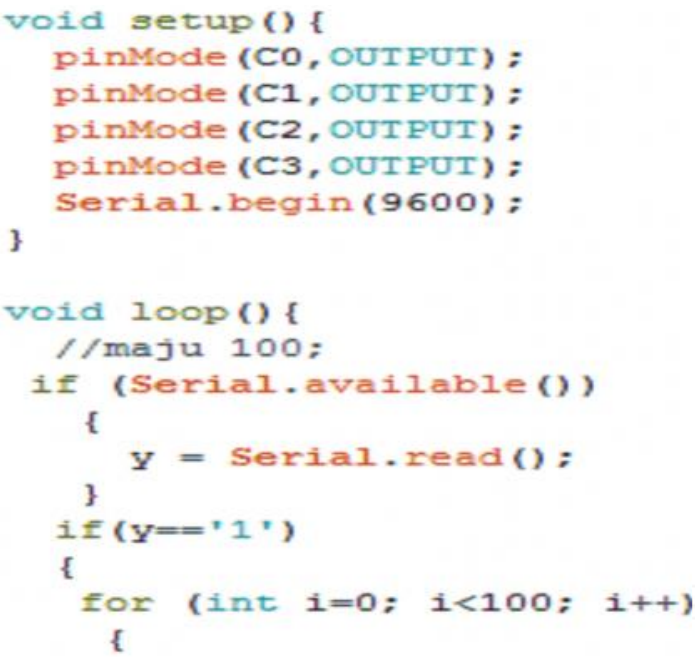

1.Script pada arduino untuk pemanggilan port serial untuk membaca file .txt pada processing a. Void setup ()$\{\ldots\}$ : Semua kode dalam kurung kurawal akan dijalankan hanya satu kali saja pada saat program arduino dijalankan.

b.PinMode : Digunakan untuk menetapkan mode dari suatu pin, pin adalah nomor pin yang akan digunakan. Mode adalah INPUT atau OUTPUT.

c. Serial.begin(9600): berfungsi untuk membuka port komunikasi serial untuk mengirim data kembali kekomputer dengan kecepatan 9600 bit per detik

d.Void loop( ) : Digunakan untuk menulis program yang akan dieksekusi secara berurutan

e.If(serial.available()) : fungsi untuk memeriksa apakah ada data yang diterima

f. Serial.read() : fungsi untuk membaca karakter yang diterima

g.If(y=='1') : jika nilai dikirimkan maka motor akan bergerak maju

h.For (int $\mathrm{i}=0 ; \mathrm{i}<100 ; \mathrm{i}++$ ) : memberikan perintah untuk maju kurang lebih 100 kali

2.Script pada arduino untuk menjalankan arduino maju mundur 


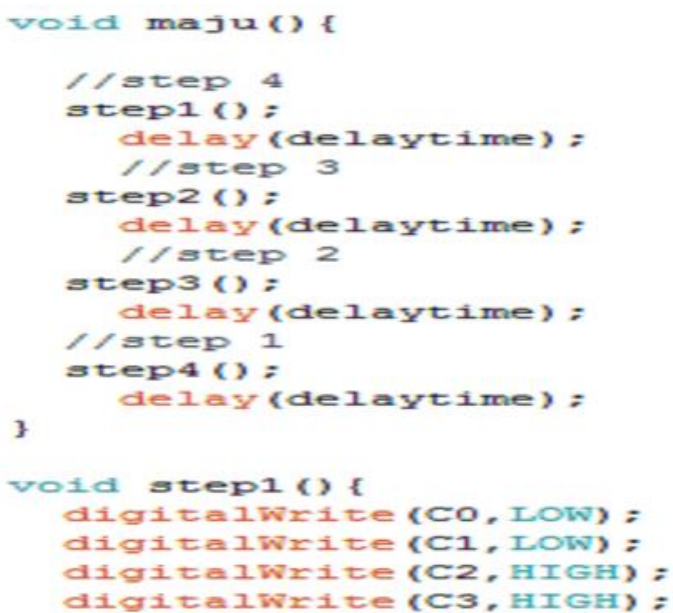

a.Delay (delaytime); : waktu penundaan sesuai yang di deklarasikan. Delaytime $=50$; 50milisekon atau 1 detik.

b.digitalWrite : pin yang ditetapkan sebagai output yang mana bila pin tersebut dijadikan HIGH maka akan ditarik menjadi 5 Volts atau LOW maka akan diturunkan menjadi Ground.

\subsubsection{Pembuatan Program pada Processing}

Pada aplikasi processing digunakan untuk menuliskan program untuk membaca file .txt 1.Script pada processing untuk memanggil file .txt menggunakan loadString dan script pada processing untuk mendeklarasikan perintah untuk dapat dan mengeksekusi agar motor dapat berputar ke arah yang dideklarasikan

string majunundur[] = loadStrings("http://localhost/ta/led.txt"); print(majumundur[ $[0]$ ); // Prints whatever is in the file ("1" or

a. portSerial = new Serial $($ this, "COM1", 9600); : memanggil serial dari arduino yang mana serial port yang dipakai arduino adalah port COM1 dengan kecepatan 9600 bit per perdetik

b.void draw() : untuk menuliskan program yang akan dieksekusi

c. String majumundur[] = loadStrings("http:// localhost/ta/led.txt”); : memasukan alamat dari file .txt

d.print (maju mundur[0]); : menampilkan apa yang ada didalam file .txt
2.Script pada php untuk pemanggilan file .txt dari processing

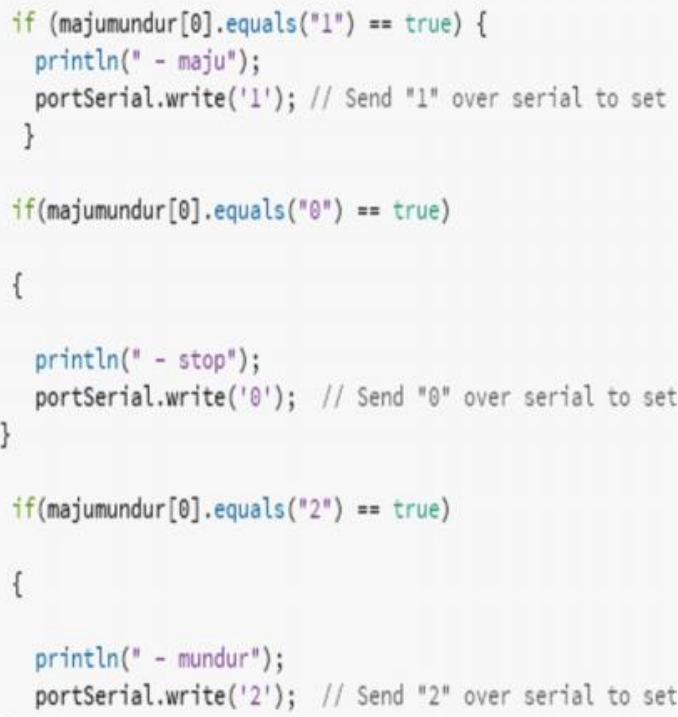

a.if (maju mundur[0].equals("1") == true) : jika kondisi yang dituliskan sama dengan satu artinya benar

b.println(“ - maju”); : untuk menampilkan perintah yang dituliskan yaitu 1 maka perintah yang ditampilkan adalah maju.

c. portSerial.write(' 1 '); : 1 dikirimkan oleh port serial untuk mengatur putaran stepper searah jarum jam

d.portSerial.write('0'); : 0 dikirimkan oleh port serial untuk mengatur putaran stepper untuk berhenti

e.if(maju mundur[0].equals(“2”) == true) : jika kondisi yang dituliskan sama dengan dua artinya benar

f. portSerial.write('2'); : 2 dikirimkan oleh port serial untuk mengatur putaran stepper berlawanan arah jarum jam

g.delay(7000); : waktu penundaan 7000 milisekon atau 700detik

\subsubsection{Menghubungkan Tincam dan Web}

Pada halaman tincam diberi tanda centang pada auto capture maka tampilan tincam akan terhubung pada web. 


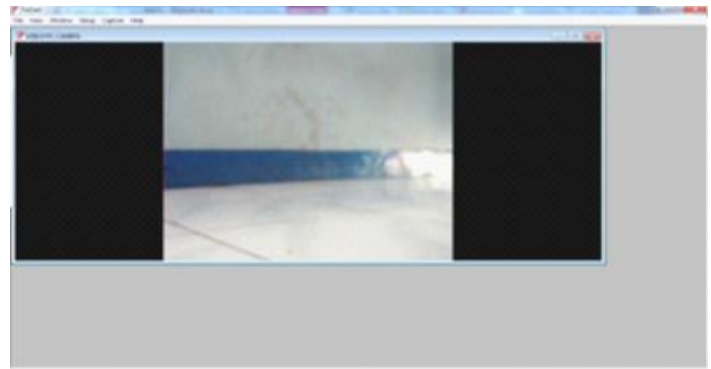

Gambar 13. Tincam Untuk Menampilkan Hasil

\subsubsection{Pembahasan Halaman Web}

1.Halaman menampilkan capture

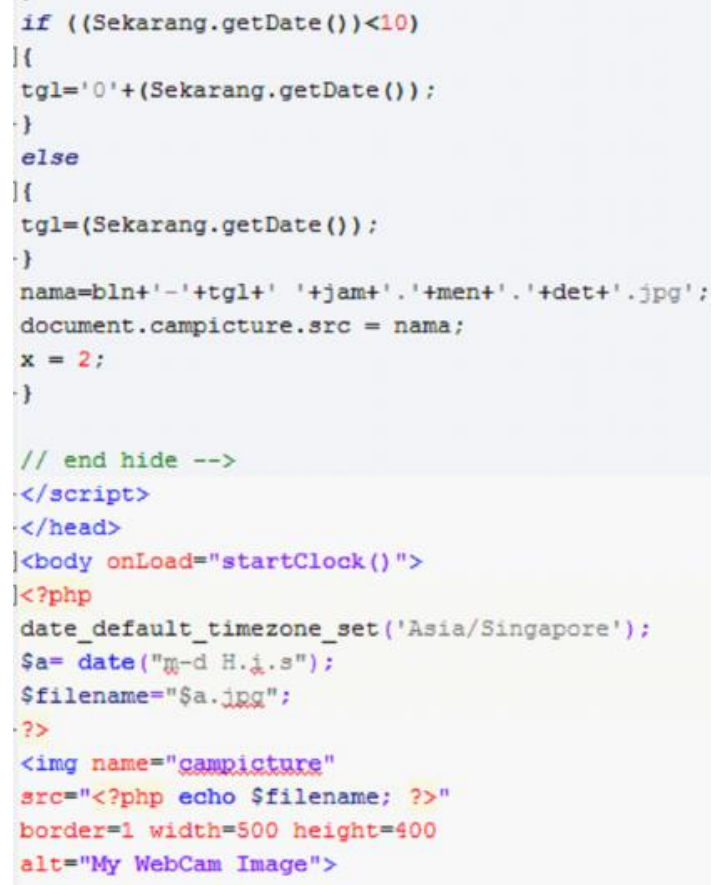

Pada halaman untuk menjalankan hasil capture menggunakan realtime sehinggan menggunakan javascript untuk menuliskan script realtime. Pengaturan waktu pun harus sesuai agar capturepun bisa tampil. Mulai dari Pengaturan Bulan dan tanggal, pengaturan waktu yaitu Jam, Menit dan detik yang harus sesuai, Area waktu pun harus diatur seperti waktu (UTC+08:00) Kuala Lumpur, Singapore harus sama.
Echo \$filename : menampilkan hasil capture dengan nama file berupa a.jpg

2.Halaman menampilkan perintah menjalankan kamera.

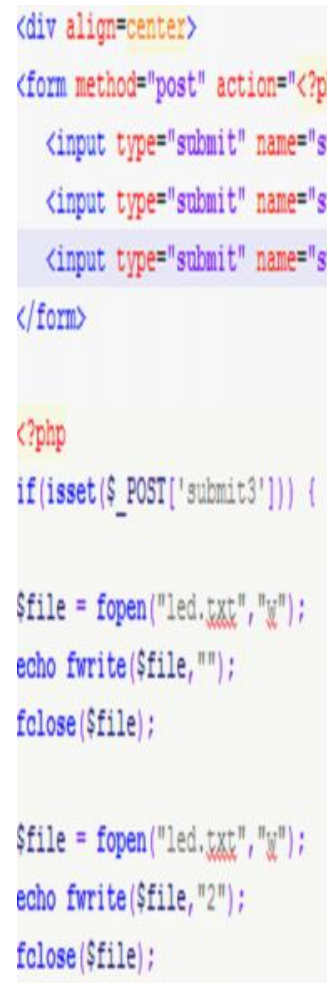

a.if(isset(\$_POST['submit3'])) : isset() digunakan untuk menyatakan variabel sudah diset atau tidak dan menangkap isi variabel dari file .txt

b. \$file = fopen("led.txt","w”); : Buka file data.txt, kemudian tuliskan isi variabel di atas kedalam

c.echo fwrite(\$file,"”); : php menampilkan file yang dibaca

d.fclose(\$file); : menutup file data .txt 


\section{Halaman interface web}

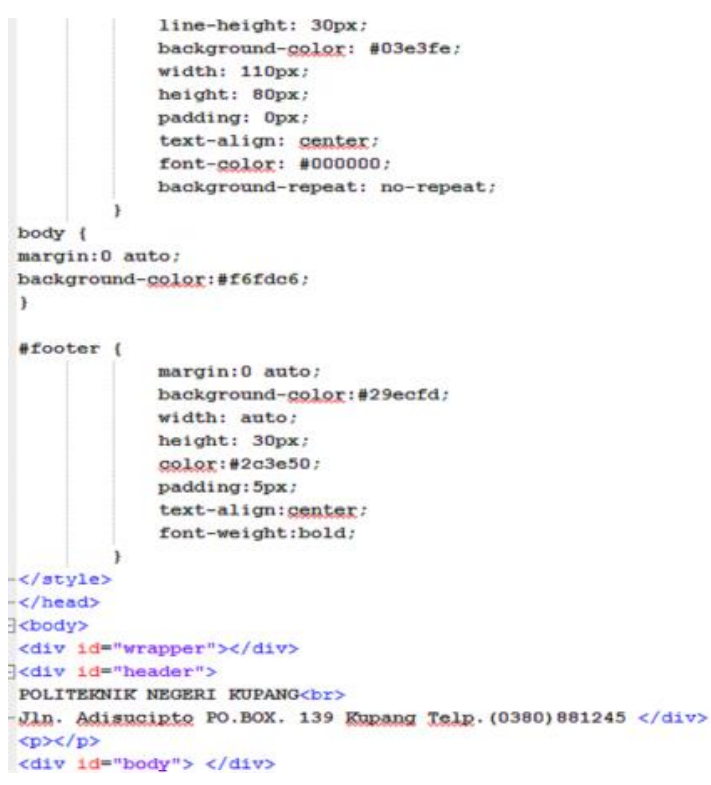

Penulisan script css untuk halaman web dan script pemanggilan css menggunakan $<\operatorname{div}\rangle\langle/ \operatorname{div}\rangle$.

\subsection{Pengujian}

Pengujian capture dari tincam yang dijalankan tampilannya pada web, dimana web menampilkan hasil capture yang sedang dijalankan.

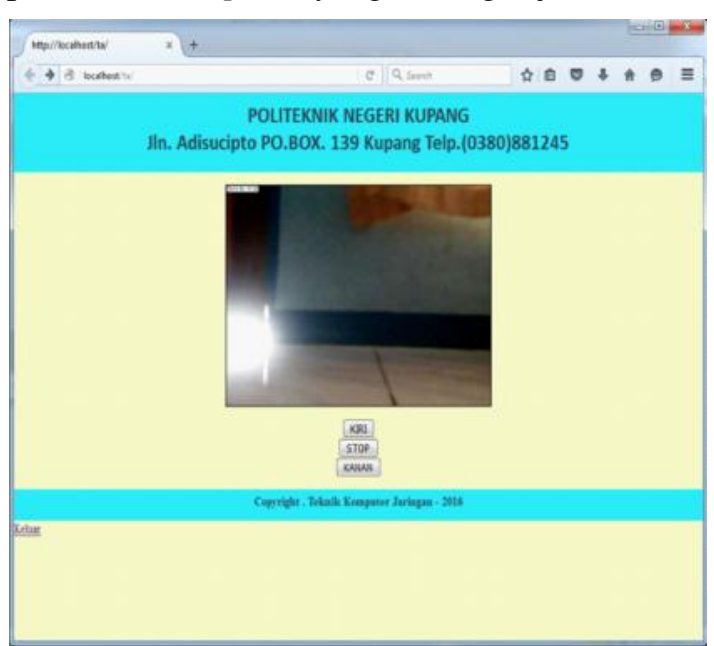

Gambar 14. Hasil tampilan web

Pada saat tombol Kiri pada halaman web di klik maka perintah tersebut akan dikirim oleh
PHP ke notepad untuk membaca file .txt yang berupa angka 1. Pada saat tersebut processing mulai memanggil file .txt yang berisi angka 1 tersebut, jika true maka perintah yang akan dijalankan adalah maju yang dikirim oleh Processing melalui port serial ke Arduino.

Pada saat tombol Kanan pada halaman web di klik maka perintah tersebut akan dikirim oleh PHP ke notepad untuk membaca file .txt yang berupa angka 2. Pada saat tersebut processing mulai memanggil file .txt yang berisi angka 2 tersebut, jika true maka perintah yang akan dijalankan adalah mundur yang dikirim oleh Processing melalui port serial ke Arduino.

Pada saat tombol Stop pada halaman web di klik maka perintah tersebut akan dikirim oleh PHP ke notepad untuk membaca file .txt yang berupa angka 0 . Pada saat tersebut processing mulai memanggil file txt yang berisi angka 0 tersebut, jika true maka perintah yang akan dijalankan adalah berhenti/stop yang dikirim oleh Processing melalui port serial ke Arduino.

Menjalankan hasil running motor stepper yang sedang berputar sesuai arah yang di eksekusi dari web untuk memutar motor stepper dari kiri ke kanan maupun dari kanan ke kiri serta mengeksekusi motor berhenti (stop).

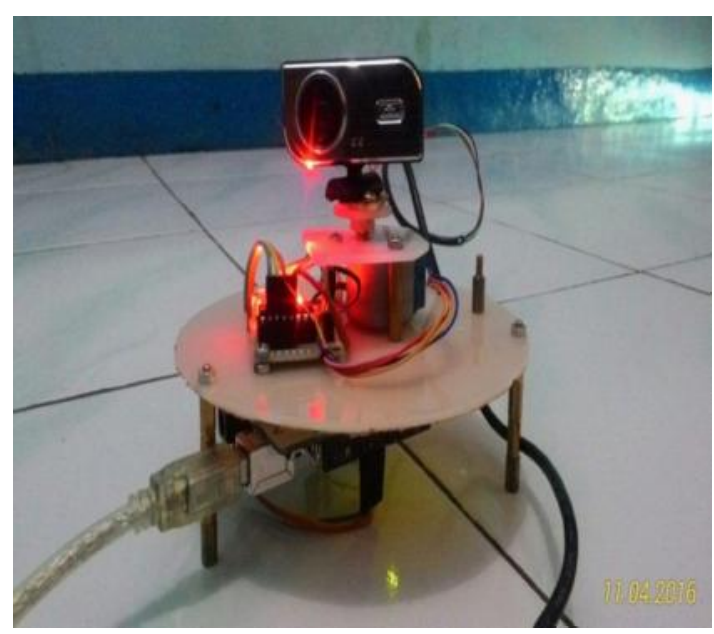

Gambar 15. Hasil runing motor stepper 


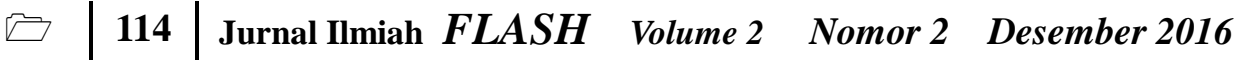

Tabel 1. Pengujian Delay dari Motor Stepper

Hasil Pengujian 1

\begin{tabular}{|c|c|}
\hline Putaran & Delay \\
\hline Kiri & $00: 00: 12: 48$ \\
\hline Kanan & $00: 00: 10: 25$ \\
\hline Kiri - Kanan & $00: 00: 30: 30$ \\
\hline Kanan - Kiri & $00: 00: 49: 95$ \\
\hline Kanan - Stop & $00: 00: 17: 56$ \\
\hline Kiri - Stop & $00: 00: 56: 82$ \\
\hline
\end{tabular}

Hasil Pengujian 2

\begin{tabular}{|c|c|}
\hline Putaran & Delay \\
\hline Kiri & $00: 00: 11: 43$ \\
\hline Kanan & $00: 00: 02: 05$ \\
\hline Kiri - Kanan & $00: 00: 40: 97$ \\
\hline Kanan - Kiri & $00: 00: 25: 90$ \\
\hline Kanan - Stop & $00: 00: 50: 05$ \\
\hline Kiri - Stop & $00: 01: 13: 82$ \\
\hline
\end{tabular}

\section{KESIMPULAN DAN SARAN}

\subsection{Kesimpulan}

Dari pembahasan pada bab sebelumnya, maka dapat penulis simpulkan sebagai berikut : 1.Untuk menghasilkan sebuah perangkat yang bisa digunakan untuk mengontrol arah gerak webcam berbasis web maka dibutuhkan aplikasi arduino untuk menjalankan motor stepper, pada motor stepper sendiri untuk membaca perintah dari web membutuhkan aplikasi tambahan yaitu processing.

\subsection{Saran}

Penulis memandang perlu untuk menyampaikan saran dari hasil kesimpulan diatas sebagai berikut:

1.Pada pengembangan harus menggunakan aplikasi yang tepat agar pada saat menjalankan motor stepper tidak membutuhkan dellay yang cukup besar.

2.Bagi para peneliti yang ingin mengembangkan penelitian ini diharapkan agar menambahkan motor stepper untuk dapat digerakan ke atas dan ke bawah.

\section{DAFTAR PUSTAKA:}

Alankts, 2015. Pengertian http, https, url, ftp, domain | definisi http https://alanktwentyseven. wordpress.com/2015/03/11/pengertian- http-https-url-ftp-domain-definisi-http/ Diakses pada tanggal 05 September 2015.

Azikin, A. 2005. Kamera Pengawas Berbasis Open Source. Elex Media Komputindo: Jakarta.

Budiharto, W. 2008. Panduan Praktikum Mikrokontroler AVR ATmega16. Elex Media Kumpotindo: Jakarta.

De-Techno, Materi Universal serial bus. https:/ /de-tekno.com/2015/11/berbagai-jenis-danversi-kabel-usb/. Diakses pada tanggal 17 Oktober 2015.

Dudung, 2016. Pengertian, Komponen Dan Fungsi XAMPP Lengkap Dengan Penjelasannya http://www.dosenpendidikan.com/tag/fungsi-xampp/. Diakses pada tanggal 17 Oktober 2015.

Farhana. 2015, Februari 25. Pengertian Web camera. http://www.logitech.com/en-gb/ product/webcam-c170. Diakses pada tanggal 19 Agustus 2015.

Himaone, 2008. Dasar Motor Stepper, http:// www.ilmu. $8 \mathrm{k} . \mathrm{com} / \mathrm{pengetahuan/}$ stepper.htm. Diakses pada tanggal 17 Oktober 2015.

Ilham, E. 2016. Pengertian dan Kelebihan Arduino. https://www.it-jurnal.com/pengertiandan-kelebihan-arduino/. Diakses pada tanggal 17 Oktober 2015.

Lorensen, dkk. 2012. Tincam. www.tincam.com. Diakses 17 Oktober 2016.

Muslimin. 2014. Monitoring ruangan dengan webcam yang dapat diakses melalui handphone menggunakan jaringan wi-fi. Skripsi tidak terpublikasi. Semarang: Universitas Diponegoro. 
Mustofa, I,C. 2008. Monitoring gerakan pada ruangan menggunakan webcam dan motor stepper. Diktat tidak terpublikasi. Malang : Universitas Islam Negeri Malang.

Pamungkas. 2010, Maret 06. Pengertian tentang motor stepper. https://pamungkas 99. wordpress.com/2010/03/06/motor-stepper. Diakses pada 19 Agustus 2015.

Pitowarno. 2006. Desain Kontrol dan Kecerdasan Buatan. Andi: Yogyakarta.

Ramadan, A. 2006. Pemrograman Web database dengan PHP dan MySQL. Elex Media Komputindo: Jakarta.

Salam, A, E, U. 2012. Aplikasi sistem pemantauan ruangan, yang dilengkapi rangkaian aktuator dari dua motor stepper untuk menggerakkan webcam. Prosiding Fakultas Teknik Elektro, Volume 6, Nomor 1. Makasar: Universitas Negeri Hasanuddin.
Sianpar. 2015. Membangun Web PHP dan MySQL. Informatika Bandung: Bandung.

Syawil, M. 2013. Panduan Mudah Simulasi \& Praktek Mikrokontroler Arduino. Andi: Yogyakarta.

Wardana K. 2015. Tutorial menghubungkan Processing dengan arduino. Bali. http:// www. [TUTORIAL] Menghubungkan Processing dengan Arduino_ Miarana DIY.html.

Zuhro, M, F. 2013. Perancangan dan Realisasi Model Sistem Monitoring Ruangan Menggunakan Webcam Berbasis Mikrokontroler ATMega16. Jurnal Reka Elkomika, Volume 1, Nomor 2. Bandung: Institut Teknologi Nasional.

Zul, M, I. 2013. Arsitektur sistem pemantau ruangan berbasis web dengan menggunakan IP Camera. Jurnal Teknik Elektro dan Komputer, Volume 1, Nomor 1. Riau: Universitas Gajah Mada. 